\title{
LA DIPLOMACIA CULTURAL DE JAIME TORRES BODET, EMBAJADOR DE MÉXICO EN FRANCIA (1954-1958)
}

Marcio Orozco Pozos*

\begin{abstract}
RESUMEN: Los estudios acerca de la diplomacia cultural son prácticamente inexistentes en la historiografía mexicana. Este artículo busca explorar un ejemplo de esta rama específica de la diplomacia. El contexto de la guerra fría nos era propicio para funciones diplomáticas de este estilo. Sin embargo, con la experiencia acumulada en el campo de la literatura, de la política y de la diplomacia cultural internacional, el Embajador Jaime Torres Bodet, de 1954 a 1958, presentó una imagen de la cultura mexicana atractiva y realizó un gran número de iniciativas culturales con la colaboración de personalidades de primer plano en la ciudad de París.
\end{abstract}

PALABRAS CLAVE: relaciones internacionales, política exterior, diplomacia, cultura, historia de México, Francia, UNESCO, Ruiz Cortines, Torres Bodet.
ABSTRACT: Studies regarding cultural diplomacy are practically non-existent in Mexican historiography. In this article, we analyze an example of such area of diplomacy. The Cold War did not provide a prosperous environment for such cultural exchanges. Yet, Ambassador Jaime TorresBodet managed to present an attractive view of Mexican culture, by implementing numerous cultural events in Paris from 1954 to 1958, aided by influential members of society and his vast experience in literature, politics, and international cultural diplomacy.

KEYWORDS: international relations, foreign policy, diplomacy, culture, Mexican history, France, unesco, Ruiz Cortines, Torres Bodet.

* Instituto Tecnológico de Estudios Superiores de Monterrey, Campus Puebla. 


\section{LA DIPLOMACIA CULTURAL DE JAIME TORRES BODET, EMBAJADOR DE MÉXICO EN FRANCIA (1954-1958)}

\section{Introducción}

$\mathrm{E}_{\mathrm{n} \text { diversos estudios acerca de la }}$ diplomacia, en muchas ocasiones la promoción cultural de México en el extranjero pasa a segundo plano. Es el caso, por ejemplo, del reciente estudio del decano del cuerpo diplomático Ismael Moreno Pino. ${ }^{1}$ Sin embargo, las recientes publicaciones acerca de los escritores en la diplomacia, en particular en el siglo XX, ${ }^{2}$ dejan abierta la puerta para un gran número de inves-

${ }^{1}$ Ismael Moreno Pino, La diplomacia. Aspectos teóricos y prácticos de su ejercicio profesional, 2001, México, Fondo de Cultura Económica-Secretaría de Relaciones Exteriores.

${ }^{2}$ Cfr. Secretaría de Relaciones Exteriores, Escritores en la diplomacia mexicana, 1998 (t. I), 2000 (t. II), 2003 (t. III), México, (SRE) Secretaría de Relaciones Exteriores. tigaciones acerca de lo que podríamos llamar la "diplomacia cultural".

El escritor o el poeta, por los privilegios de su formación, en muchos casos conoce a la cultura de su país de manera especial. El escritor mexicano desde tiempos del Ateneo de la Juventud busca, además, ser "dueño de su cultura". ${ }^{3}$ Eso le permite en casos señalados hacer que la principal tarea confesada sea la promoción de la cultura nacional. En sus Memorias, Jaime Torres Bodet, recuerda que durante los años de trabajo como Embajador "tendría que consagrar mi mejor esfuerzo a la misión cultural de la embajada". ${ }^{4}$

${ }^{3}$ Jaime Torres Bodet, Memorias, 1981, México, Porrúa, vol. II, p. 107.

${ }^{4}$ Ibid., p. 306. 
Jaime Torres Bodet, hombre de letras y político mexicano, concluyó la carrera diplomática que empezó en 1929 con un período que dedicó a ser el embajador de México en Francia. En 1954, ${ }^{5}$ fue enviado por el presidente Adolfo Ruiz Cortines como su representante en París. Dejó esta responsabilidad al finalizar el sexenio, en octubre de 1958. Se puede decir que concluyó una carrera de este tipo con un cargo que correspondía a su larga experiencia política y no fue enviado sólo por ser una persona de confianza del presidente mexicano.

El diplomático que nos interesa fue un integrante central de la generación literaria de los Contemporáneos. Sus dos grandes mentores políticoliterarios fueron dos integrantes de la constelación del Ateneo de la Juventud: José Vasconcelos por una parte, Alfonso Reyes por otra. En primer lugar, en 1920 Torres Bodet trabajó como secretario particular del rector de la Universidad Nacional, y en 1921 ocupó la misma función con el nuevo secretario de Educación Pública de Álvaro Obregón. Se encargó en 1922 del departamento de Bibliotecas. Después de 1929 se distanció poco a poco de Vasconcelos. En segundo lugar, siguió la huella de Alfonso Reyes, desde 1929, cuando

${ }^{5}$ Esto ocurre después de unas semanas de convalecencia por una operación quirúrgica en la cual había perdido un ojo, cfr., ibid., p. 307. -después de mucha insistencia por parte de este último- decidió examinarse y entrar en el cuerpo diplomático de carrera. Fue diplomático profesional largos años, como Reyes. ${ }^{6}$ En 1934, por ejemplo, la emulación torresbodetiana se extiende al ejercicio profesional de la diplomacia. ${ }^{7}$ Recién adscrito a la Embajada de México en Buenos Aires, hizo, antes de llegar a su destino final, una escala en Río de Janeiro para conversar con el Embajador Alfonso Reyes (1931 a 1935).

El término "diplomacia cultural" es empleado en este ensayo como el

${ }^{6}$ De 1916 a 1939 Alfonso Reyes ejerce cargos diplomáticos. Jaime Torres Bodet lo hizo de 1929 a 1940. Finalmente, de 1954 a 1958. Fernando Curiel aborda a los dos escritores describiendo dos vidas paralelas. Lo es hasta cierto punto, puesto que Alfonso Reyes no se dedicó tanto tiempo a cargos políticos como Torres Bodet, que fue Secretario de Educación Pública en el sexenio de Manuel Ávila Camacho, de 1943 a 1946, y durante todo el gobierno deAdolfo López Mateos, de 1958 a 1964. Fue además Secretario de Relaciones de 1946 a 1948 antes de ser nombrado Director general de la UNESCO. A este respecto, ver Fernando Curiel, Casi Oficios. Cartas cruzadas entre Jaime Torres Bodet y Alfonso Reyes (1922-1959), 1994, México, El Colegio Nacional.

${ }^{7}$ Alfonso Reyes, Misión diplomática, 2001, México, Secretaría de Relaciones Exteriores-Fondo de Cultura Económica, t. I, prólogo de Víctor Díaz-Arciniega. A propósito de la experiencia diplomática de Reyes, este último escribe en 1933, un año antes de su encuentro con Torres Bodet, un ensayo escrito a petición del entonces Secretario de Relaciones Exteriores, José Manuel Puig Cassauranc, acerca del trabajo diplomático: "El servicio exterior mexicano". Este ensayo se encuentra el libro citado. Ver pp. 124-68. 
NOTAS

trabajo exclusivamente diplomático que busca, en los términos de una relación amistosa entre dos países, dar a conocer la cultura nacional. El ensayo por lo tanto, permitirá conocer la visión oficial y torresbodetiana de este concepto. Despejará un tanto el conocimiento de las relaciones públicas del Embajador y dará a conocer sus capacidades de propagandista cultural.

La diplomacia cultural no era una función nueva para Jaime Torres Bodet. La ejerció en pleno al tiempo de su cargo como director general de la UNESCO, de 1948 a 1952. Buscó el acercamiento de las naciones en la posguerra mundial por medio de la comunicación de las culturas nacionales representadas en la UNESCO. Por otra parte e independientemente de la diplomacia, la difusión cultural fue una rama de su trabajo como secretario de Educación Pública, de 1943 a 1946, compatible con la campaña de alfabetización. La diplomacia profesional, base para el trabajo de promoción cultural, es una rama con la cual está muy familiarizado el Embajador: era político en plena madurez, que conoció el trabajo de secretario de Relaciones Exteriores de 1946 a 1948.

Este ensayo busca realizar una síntesis del trabajo diplomático encaminado a dar a conocer "lo mexicano", así como su arte y cultura. En una primera parte se estudiará la diplomacia cultural como la afirmación de una idea de México, principalmente su desarrollo como nación. En segundo, las empresas culturales del embajador Jaime Torres Bodet.

\section{La imagen de México}

Los esfuerzos diplomáticos de un país no sólo se concentran en lo económico y político. Conceden un peso importante al conocimiento recíproco y al intercambio cultural. En la esfera de la cultura, no nos limitamos es este texto a la producción artística y literaria, sino a la manera de ser de un pueblo, sus tradiciones históricas, las mentalidades, los estereotipos. No somos insensibles al hecho que en la historia de siglo XX por lo menos, la valoración de las culturas propias y ajenas guarda una estrecha relación con la ideología política. En la segunda parte del siglo XX, un país como México, defiende mediante su diplomacia unaidea de México que se presenta una vez más como país civilizado y moderno.

En este contexto, Torres Bodet participó en varias polémicas a propósito de la imagen de México en Francia. Me limitaré a comentar dos episodios en los cuales el embajador defiende la cultura nacional contestando, como 
jefe de misión diplomática, a lo que consideró una afrenta. ${ }^{8}$

El libro fue leído y criticado por el embajador y responde al autor en una carta personal. La traducción de esta carta está incluida en el segundo informe diplomático de la Embajada de México que se refiere a este escrito, con fecha del 10 de enero de 1956. El primero, fechado el 5 de enero, sugiere no protestar por las apreciaciones desfavorables a México teniendo en cuenta que la editorial y el autor no

${ }^{8}$ Mezclado entre los informes económicos de la Embajada de México en París, está un informe de dominio cultural elaborado en la Embajada de México en Londres. Se refiere al mismo libro publicado por el autor francés A. T'Serstevens y traducido al inglés: Mexico, Three-Storeyed Land, Hutchinson of London, 1959. La publicación en inglés se lleva a cabo unos años después de la versión en francés. El informe de "Embamex Londres" es extremadamente negativo: "es deplorable que una obra de esta clase, que ciertamente no puede considerarse favorable a México, haya sido traducida al inglés y publicada aquí donde es posible que tenga una amplia circulación ya que es una obra recomendada por la "Book Society". Además está magníficamente ilustrada". El libro se anexaba originalmente en el mismo informe. En los archivos no se encuentra este libro. Cfr. Archivo Histórico Genaro Estrada (AHGE) III-1746-4. Informes económicos. 0821 (Exp. 42.0-910-3 “59”) Informe de Pablo Campos Ortiz desde Londres. La edición francesa está bellamente ilustrada, como se lee en Archivo personal de Jaime Torres Bodet en el Centro de Estudios de la Universidad (APJTB, CESU-UNAM), Embajada en Francia Apartado I-polémicas. Un libro de un observador extranjero es favorable o desfavorable. Rara vez es neutro. La diplomacia del prestigio o de la reputación nacional es un factor importante, poco analizado por Ismael Moreno Pino en la ya citada obra. tenían ningún contacto con la Embajada. Sin embargo, la situación cambia el día 7. El editor "remitió un ejemplar del (Le Mexique. Un pays a trois étages, Arthaud, Paris) libro "México, país de tres pisos" (sic), con atenta dedicatoria del autor. Ese acto [dejaba] entender que ambos [consideraban] el libro interesante para México".

El Embajador "aprovechó la ocasión y criticó con firmeza pero con tacto el libro, de manera que no haya lugar a ulterior polémica, ni menos aún a llevar el asunto a las columnas de un periódico."

El Embajador criticó la actitud un tanto despectiva del escritor francés y señaló que el modernismo mexicano responde a la necesidad de adaptarse al crecimiento rápido de la población. Apuntó que ésta "en un tercio de siglo se ha duplicado". El embajador percibió, en el autor europeo, una "indiferencia frente a los problemas históricos y sociales". El indígena parecía ser objeto de desprecio en la descripción de T'Serstevens: "los mendigos otomíes son comparados con los monos". Los indígenas aparecen "tan reservados y tan estoicos". Y al finalizar su escrito encontraba el diplomático una contradicción: el interés de México no está tanto en su cultura y sus logros materiales sino en la grande-

${ }^{9}$ APJTB, CESU-UNAM, Embajada en Francia Apartado I-Polémicas, p. 21. Se incluye una copia del informe diplomático del 10 de enero y la respuesta de A. T'Sterstevens del 11 de enero de 1956, p. 11-2. 
NOTAS

za de su "raza india". Sobre todo lo criticable, según Jaime Torres Bodet, fue que "del esfuerzo que han hecho los mexicanos para organizar su progreso en condiciones sumamente duras" advertía el embajador pocas huellas en las 435 páginas del libro. Daría la impresión al terminar de leer la carta de Torres Bodet que aprovechaba la ocasión para disertar acerca del progreso material del país en las últimas décadas. Disponía de datos estadísticos concretos (decenas de miles de educadores, treinta mil kilómetros de carreteras en treinta años, etc.) y era parte del discurso típico de la época del "desarrollo estabilizador" del Estado Mexicano.

En otra ocasión la afrenta trascendió a la prensa escrita. El 5 de febrero de 1955, Torres Bodet, escribió al director del periódico L'Aurore para hacer una protesta. Henri Troyat, conocido escritor francés, había escrito un reportaje sobre México. Troyat criticaba al gobierno mexicano por boca de un personaje anónimo y causó la reacción del embajador. “¿Por qué señala, en efecto, tan a la ligera los detalles de lo que desaprueba y en cambio insiste con tal acritud sobre cuanto no tiene la suerte de agradarle? Un país en un todo. Quien no observa sino las dificultades, las complicaciones, desfigura lo esencial". ${ }^{10}$

${ }^{10}$ APJTB, CESU-UNAM, Embajada en Francia, Apartado I-polémica, p. 1.
Torres Bodet, después de señalar la visión superficial de Troyat, pedía al autor francés que concediera "más atención a las manifestaciones del progreso". ${ }^{11} \mathrm{Al}$ director comenta: "estimo justo recordar a los lectores de su diario [...] algunos aspectos de un progreso que el Sr. Troyat declaró 'falso' desde el segundo día de su estancia en México. Piense lo que piense, ese progreso no está destinado al uso exclusivo de una minoría". El embajador quería refutar esta visión elitista del desarrollo mexicano. Esta refutación es la parte más larga de la carta, un recuento estadístico de los servicios públicos mexicanos: la educación (el gasto de 1922, 20 millones de pesos era comparado con el de 1955, 712 millones); la Universidad Nacional (32,000 en la década de 1950 comparado con 2,580 en 1921). Los presupuestos más elevados eran los de comunicaciones y los de educación, con un porcentaje de 16 y 12 por ciento del erario público, respectivamente. La infraestructura no era como la describía Troyat "ineficiente" por parte de sus técnicos: comparado con el año 1936 -antes de la expropiación- la producción de barriles de petróleo por año era de 40 millones; en 1951 la producción era $78,780,487$ barriles. Terminaba el Embajador citando a importantes representantes de la vida pública france-

${ }^{11} \mathrm{Ibid} ., \mathrm{p} .2$. 
sa que habían realizado ya viajes a México: Paul Rivet, representante de la Comisión Nacional Francesa de la UNESCO; Jean Sarrailh, rector de la Universidad de París; y Marc Blancpain, Secretario General de la Alianza Francesa. El escrito fue contundente. La carta fue publicada en L'Aurore pocos días después. ${ }^{12}$ Quiso darle publicidad en México y se tradujo al español en un periódico capitalino. ${ }^{13}$

Otro esfuerzo por defender una imagen oficial y positiva de México fue la entrevista concedida en el periódico Combat acerca de la educación en México. Cabe señalar que Combat, con L'Aurore, Le Monde, Le Figaro, y Le Parisien libéré eran en ese entonces los más importantes en la capital francesa. En esa entrevista, Jaime Torres Bodet definía la postura gubernamental. Con motivo del inicio del programa de la Beca Hidalgo, responde a preguntas acerca de la educación en México. ${ }^{14}$ Este apoyo económico a la investigación académica tuvo como fin recompensar, con un premio de más de quinientos mil francos, ${ }^{15} \mathrm{el}$

${ }^{12} I b i d$., p.14.

${ }^{13}$ Ver artículo "Turismo y cultura", ibid., p. 24 bis.

${ }^{14}$ Jaime Torres Bodet, Memorias, 1981, México, Porrúa, vol. II, p. 307.

${ }^{15}$ La tasa de cambio, siendo 350 francos por un dólar el día 4 de junio de 1952, el estímulo de la beca fue originalmente de aproximadamente de 1500 dólares al terminar la década. Ver AHSRE-Concentraciones UNESCO XII-446-25 (clasificación topográfica). Dossier: Asamblea General de la UNESCO Renuncia del Director general. estudio de un profesor que se esforzara por esclarecer algún punto de nuestra historia. Esta beca benefició a importantes historiadores franceses, entre quienes destacaron especialistas del Medioevo como Jacques Heers y Jacques Le Goff. ${ }^{16}$ En sus respuestas, el Embajador señalaba las razones del nombre de Hidalgo para la beca: Hidalgo fue también francés por sus lecturas y su conocimiento de las ideas de la Ilustración en el siglo XVIII. La beca pretendía conseguir un conocimiento más profundo de México y América Latina en Francia.

También respondió a preguntas acerca de los principios de la enseñanza en México, de la enseñanza técnica, la especialización y la conciencia de los problemas internacionales. A propósito de los principios de la enseñanza, el embajador señalaba que eran promovidos los principios democráticos, formando una autonomía moral del educando. Incluía cifras estadísticas importantes acerca del desarrollo educativo en México; informaba que se gastaban 20,000 millones de francos (13 por ciento del presupuesto federal) al año para más de dos millones de niños en escuelas primarias federales. Más del doble que en 1921. El doble de escuelas primarias que en

${ }^{16}$ Jacques Heers escribió por lo menos un artículo acerca del arte virreinal en México en Nouvelles du Mexique, núm. 11, 1957, Biblioteca Daniel Cosío Villegas, (El Colegio de México), 917.2005 N934 
NOTAS

1921 y casi el triple de maestros. No podía dejar pasar una mención a la campaña nacional en contra del analfabetismo que él mismo había dirigido. También la menciona en la carta a Robert Lazurick, director del periódico L'Aurore, en 1955. En una gráfico exponía más cifras: de 4.8 millones de inscritos en esta campaña, fueron alfabetizados 3.6 millones en los centros de enseñanza. Respecto a la enseñanza técnica comentaba la importancia del Instituto Politécnico Nacional, la Universidad Nacional con sus institutos y la Universidad Técnica Agraria de Chapingo. Citando a Gabino Barreda y al secretario de Educación Pública, defendía la importancia de la igualdad en la educación. Habló de la idea de un necesario espíritu de síntesis que complemente la especialización. Alabó en México la educación cívica y el estudio de los problemas internacionales en los programas de educación secundaria. Terminó la entrevista con un comentario acerca del artículo tercero constitucional (reformado por el mismo Torres Bodet, quién fungió como secretario de Educación Pública durante el sexenio de Manuel Ávila Camacho): a) la educación es democrática en el sentido más amplio, el del mejoramiento social. b) contribuye a la independencia nacional en todos sus aspectos. c) promueve la convivencia humana dentro y fuera del país. En la entrevista se entrevé en todo momento la experiencia del antiguo director general de la UNESCO.

\section{Las empresas culturales del Embajador de México}

Las empresas fueron en un primer momento proyectos. Antes de salir a París, en octubre de 1954, dedicó el último mes en México a estudiar la situación francesa, revisando los informes diplomáticos enviados por el embajador saliente Jiménez O'Farril a la Cancillería. Estudió los proyectos que preveía realizar desde finales del año 1954 como Embajador de México en Francia. Son numerosas, según lo da a entender Salvador Novo - "compañero de generación" en la revista Contemporáneos-y el propio Torres Bodet. ${ }^{17}$ Se lee en las Memorias del embajador que antes de salir de

${ }^{17}$ Comenta al respecto en sus crónicas periodísticas - que después formaron parte de sus libros acerca de los sexenios correspondientes- el 26 de febrero de 1955: "ya se acuerda usted de cuántos proyectos interesantes llevaba al irse a París". Ver Salvador Novo, La vida en México en el periodo presidencial de Adolfo Ruiz Cortines, vol. II, 1996, México, CONACUlTA, "Memorias mexicanas", p. 41. También en carta a Alfonso Reyes, el 30 de noviembre de 1954 , le recuerda su amable ofrecimiento de "sintetizar en unas cuartillas lo que acerca de México conviene saber" y agrega poco más abajo: “desde mucho antes de emprender el viaje advertí la necesidad de disponer un texto de esa índole", cfr. Fernando Curiel, Casi Oficios..., op. cit., p. 150. 
México, al despedirse de sus pares del Colegio Nacional, les "había manifestado que uno de sus propósitos era el de publicar en París una revista mexicana". Se difundiría ahí "nuestra historia, nuestra literatura, nuestras obras de arte, nuestros progresos científicos, la actividad de nuestras empresas agrícolas e industriales y la amplitud de nuestras realizaciones en materia de educación y de irrigación, seguridad social, salubridad, comunicaciones y obras públicas." Llegaba la hora de convertir los deseos en plan de trabajo.

Nouvelles du Mexique (Noticias de México) fue la primera gran empresa cultural de la Embajada en el período 1954-1958. Esta revista era de gran calidad editorial. El proyecto consistía en una edición en treinta y dos páginas con abundantes ilustraciones. Se solicitó el financiamiento de la Secretaría de Relaciones Exteriores y del Banco de México. La revista tuvo el apoyo de Luis Padilla Nervo, desde la Cancillería; de Rodrigo Gómez, presidente del Banco de México; de Antonio Carrillo Flores, desde la Secretaría de Hacienda.

En junio de 1955 apareció la revista cubriendo los meses de abril y de mayo. De septiembre de 1955 a mayo de 1958, fueron editados once números más. En su mayoría circulaban en Francia pero también circulaban en otros países de Europa, gracias a la colaboración que ofrecieron los colegas en las distintas embajadas y consulados de Europa. Los países en cuestión fueron: Dinamarca, Gran Bretaña, Holanda, Italia, Noruega, Polonia y Suecia. Son países donde el francés tenía mucho peso. La revista Nouvelles du Mexique sigue publicándose en París actualmente.

La aparición de la revista Nouvelles du Mexique coincidió con una de las exposiciones más importantes en tiempos de la Embajada torresbodetiana. Se trata de la Exposición del libro mexicano. La auspiciaron las Secretarías de Relaciones Exteriores y de Educación Pública, y los Ministerios franceses de Asuntos Extranjeros y de Educación. Se trataba también de una actividad oficialmente auspiciada por la Universidad de París (Sorbona). Al acto inaugural asistieron el Sr. Antoine Pinay, ministro de Asuntos Extranjeros francés; el rector Jean Sarrailh, y Julien Cain, director de la Biblioteca Nacional Francesa (es decir, uno de los dos archivos más importantes de Francia). Además, estuvieron presentes representantes del cuerpo diplomático latinoamericano, el conde de Billy, presidente de la Casa de América Latina y varios intelectuales franceses entre los cuales figuraba Paul Rivet.

En la exposición alternaban libros franceses y mexicanos. Julien Cain se 
NOTAS

había encargados de exponer libros antiguos franceses que disertaban acerca de México, desde Thévet (1558) hasta Aubin y Brasseur de Bourbourg, etc. La exposición dio lugar a que académicos franceses y mexicanos dieran alguna conferencia. Marcel Bataillon abordó el tema "México, ciudad de libros y de bibliografía". Ignacio Bernal, agregado cultural de laEmbajada, habló acerca de "Tenochtitlán, capital del mundo indígena”. Silvio Zavala, ${ }^{18}$ otro invitado, participó también comentando la relación existente entre el indio y el europeo en la historia de México.

Otro hito importante en las empresas de diplomacia cultural fue el curso sobre economía mexicana. ${ }^{19}$ Se trató de una actividad de la Escuela de Altos Estudios sobre la América Latina de la Universidad de la Sorbona. Siete conferenciantes mexicanos participaron. René Espinoza Olvera, (agregado comercial de la Embajada); Jenaro González Reyna; Manuel de la Lama; Roberto Martínez Le Clainche; Raúl Medina Mora; Gonzalo Ortiz, y Eduardo Villaseñor. Invitado Torres Bodet por el rector Sarrailh,

${ }^{18}$ Pocos meses después sustituyó a Ignacio Bernal como agregado cultural.

${ }^{19} \mathrm{El}$ despacho correspondiente al curso de economía tiene un lugar señalado en el Archivo personal de Jaime Torres Bodet: APJTB, CESU-UNAM, Embajada en Francia. Consta de un resumen u orden del día seguido de una serie de comentarios largos. los dos inauguraron el curso. Después de las palabras de Sarrailh y el discurso del Embajador, Espinoza Olvera disertó acerca de la demografía mexicana. Los temas abordados por mexicanos y franceses fueron: la propiedad rural y la agricultura; la irrigación; la industria química, la industria eléctrica, minera, del petróleo, del hierro y del acero, de manufactura; "Les Charbonnages du Mexique vus par un ingénieur des Charbonnages de France (La minería mexicana abordada por un Ingeniero de Charbonnages de France)", la industria metalúrgica mexicana; la política monetaria, bancaria y comercial.

La relación con hombres de primer plano de la cultura mexicana fue un instrumento eficaz de su diplomacia cultural. El ejemplo más llamativo es Alfonso Reyes. Con este intelectual había entablado ya desde los años veinte -más precisamente desde 1922- una correspondencia que el mismo joven colaborador de José Vasconcelos promovió. La correspondencia entre los dos personajes públicos y literarios consta, según Fernando Curiel, de tres etapas. ${ }^{20} \mathrm{La}$ primera recorrió dos décadas, de 1922 a 1939. La segunda, de la década de 1940 hasta diciembre de 1948, cuando Jaime Torres Bodet, electo como

${ }^{20}$ Fernando Curiel, op. cit., pp. 14-5. Ver también pp. 121-3. 
director general de UNESCO, invitó a Alfonso Reyes a colaborar con la institución, representando a México. Finalmente, de la década de los años 1950 hasta la muerte de Alfonso Reyes en 1959. Este tercer trecho es el único que nos interesa aquí; no sólo porque ilumina los últimos años parisinos de Jaime Torres Bodet como Embajador, sino además porque se trata del período en el cual la extensión de la correspondencia es la más importante. Por sí sola representa la mitad de las cartas intercambiadas entre los dos escritores a lo largo de los casi cuarenta años de intercambio. ${ }^{21}$

Reyes fue un colaborador asiduo de Torres Bodet en sus empresas culturales como embajador de México. Tal es, en lo esencial, la historia de este tercer momento de su correspondencia. Las cartas de la etapa diplomática en París van y vienen desde el 30 de noviembre de $1954^{22}$ hasta el 9 de julio de $1958 .{ }^{23}$ Por mencio-

${ }^{21}$ Esta afirmación se apoya en el número de páginas ocupadas por sus cartas en la recopilación de Fernando Curiel ya citada. Las páginas que conciernen la Embajada de París ocupan las páginas 151-245. El resto de la correspondencia cubre las páginas 25 a 147.

${ }^{22}$ Ibid., p. 150.

${ }^{23}$ Esta última carta está contenida en archivo privado de Jaime Torres Bodet: APJTB-Embajador de México en Francia IV-11. Adjunta está la última carta, muy estimulante para Torres Bodet, que le enviaba Reyes, a París, el 28 de junio de 1958. En ésta le felicita por su Trébol de Cuatro hojas publicado recientemente en México. Para Alfonso Reyes este poemario es la obra más bella que conoce de Torres Bodet. nar algunos asuntos señalamos: la petición de una síntesis de la literatura mexicana para los estudiantes de los Lycées (Escuelas PreparatoriasBachilleratos) franceses; la petición a Reyes de una introducción al catálogo de la exposición del libro mexicano en la Sorbona; la petición a Reyes de un texto sobre Julio Verne (cincuentenario de su fallecimiento); la recomendación (Reyes a Torres Bodet) para que se concediera una beca a Jorge Padilla, "uno de los más auténticos valores de la nueva generación intelectual"; los comentarios acerca de la celebración en la Casa de México en la Ciudad Universitaria de París, de su cincuentenario como escritor (José Bargamín, el Abate de Mendoza, Charles Aubrun); la petición a Reyes de un panorama de las letras mexicanas, "Desde los orígenes hasta el fin del siglo XIX"; la colaboración de Alfonso Reyes en la revista de la Embajada Nouvelles $d u$ Mexique.

Nos extendemos a propósito en este último tema por ser el que más páginas ocupa dentro de la correspondencia. La colaboración de Reyes en la revista de la embajada es constante. En los primeros números preparaba material acerca de los escritores mexicanos. El primer número incluye un artículo acerca de Sor Juana Inés de la Cruz. El embajador pidió a 
NOTAS

Alfonso Reyes que resumiera en unas tres cuartillas su estudio acerca de Sor Juana en México en la Cultura de 1946. Unas semanas después envió, con el texto definitivo en francés de Sor Juana, otros dos -en caso de que fueran de utilidad más adelante-acerca de Ruiz de Alarcón y otro sobre los albores del teatro en México. El 11 de febrero hizo llegar por medio del Abate de Mendoza, secretario particular de Torres Bodet en la Embajada, una "Charla sobre Francia", una serie de recuerdos acerca de la estancia de Reyes en los años veinte en París. El artículo acerca de Sor Juana publicado en la revista sirvió más tarde, con ampliaciones, para ser leída en actos "sobre México de los que se organizan no solo en París sino también en provincia". ${ }^{24}$ Más adelante, Torres Bodet pidió a Reyes que enviara el texto acerca de la pintura de Diego Rivera que quería insertar en Nouvelles du Mexique. La publicación del texto permitía enriquecer el homenaje que había recibido el pintor mexicano, organizado por la Embajada de México en París a finales del año 1956. ${ }^{25}$ En el número 9 de la revista

${ }^{24}$ Fernando Curiel, op. cit., pp. 14-5. Ver también p. 215.

${ }^{25}$ El texto es "Diego Rivera cumple los setenta" en Alfonso Reyes, Obras completas, t. XXII, 1989, México, Fondo de Cultura Económica, pp. 715-6. Por su brevedad convenía perfectamente a la naturaleza de la revista. Ver carta de Jaime Torres en Curiel, op. cit., p. 219. quedaba incluido un fragmento del estudio acerca de las letras patrias de Reyes durante el siglo XIX en México en la Cultura. La traducción había sido previamente revisada por Silvio Zavala, el agregado cultural. Este número correspondió a la conmemoración centésima de la Constitución liberal de 1857. El artículo correspondía de manera ajustada al tema. ${ }^{26} \mathrm{El}$ fragmento del ensayo de Reyes corresponde a una conferencia leída en su nombre en la casa de México. Lleva por título en la revista "La literatura mexicana desde la independencia hasta la victoria de la causa liberal". Más adelante en el número 11 de la revista se publica el segmento -relativo a la independencia- de la conferencia de Alfonso Reyes sobre las letras patrias.

Finalmente, el embajador fue un activo impulsor de la diplomacia cultural mexicana por medio de la actividad académica internacional. Abusando de la terminología, podríamos llamar a esta actividad "diplomacia cultural parlamentaria", en el sentido en el que Ismael Moreno Pino define las labores de la diplomacia parlamentaria: participación diplomática en los foros internacionales promoviendo situaciones favorables políticamente para México. ${ }^{27}$

${ }^{26} \mathrm{Ibid}$., 226.

${ }^{27}$ Ver Ismael Moreno Pino, op. cit., pp. 612-3. 
Más concretamente, a la Asociación Internacional de Universidades a cuya fundación contribuyó el mismo Torres Bodet en 1950 al encabezar la UNESCO de 1948 a 1952. El 17 de septiembre llevó a cabo un viaje a Estambul. Representaba el embajador a la Universidad Nacional Autónoma de México en la Segunda Conferencia General de la Asociación Internacional de Universidades. La sede de la conferencia fue la Universidad de Estambul. La conferencia duró una semana. Jean Sarrailh, rector de la Sorbona de París, elogió en esa conferencia la labor principalmente educativa de la gestión del antiguo director general de la UNESCO, según el informe de la Embajada de México en Estambul. ${ }^{28}$

A propósito de la diplomacia parlamentaria escribe: "las gestiones -en una asamblea de organismo internacional- las llevan a cabo los miembros de las delegaciones $[\ldots]$ a través de sus intervenciones en las que fijan la postura de sus respectivas naciones frente a las cuestiones objeto de consideración, buscando que el organismo -en este caso la Asociación Internacional de Universidadesactúe de la manera más favorable que sea posible a sus intereses e impidiendo que realice actividades que podrían resultar desfavorables a estos." La resolución favorable después de la diplomacia de pasillo necesaria fue la designación de la naciente Ciudad Universitaria de México como sede de la siguiente Asamblea. Los discursos del Embajador mexicano, experimentado en diplomacia parlamentaria latino-americana y en diplomacia cultural internacional, permitió obtener ventajas para México.

${ }^{28}$ Los informes de la Embajada se encuentran en el archivo de Concentraciones. Son los informes de política internacional turca del año 1957. AHSRE-
Uno de los temas que discutiría la Asamblea era "la Universidad productora de líderes". En el discurso y las intervenciones de Torres Bodet sugirió que convendría modificar un poco la temática y discutir de preferencia éste: "La Universidad, escuela de ciudadanos". En su discurso citó a su difunto maestro, Antonio Caso, el ateneísta: "las masas triunfan por las élites que engendran, pero las élites triunfan con las masas de donde surgen". Haciendo valer su experiencia en diplomacia parlamentaria, y su gran prestigio diplomático, los delegados latinoamericanos en bloque, aparentementemente con el apoyo de la delegación francesa, obtuvieron que se suprimiese la fórmula "Leaders in National Life" (promovida por los Estados Unidos). En lo sucesivo se eliminaría el concepto de un dirigismo universitario y se apoyaría el acento, en las conclusiones de la Conferencia, sobre el deber de la acción social. ${ }^{29} \mathrm{Al}$ acercarse el final de la

Concentraciones Embamex Turquía Exp. 496-510 "55" núm. 816 reservado. Política exterior p. 6-7: "México envió como delegados a la 2da. Conferencia Mundial de Universidades a los señores Dr. Luis Garrido y al Embajador Jaime Torres Bodet. En la sesión inaugural el Sr. Jean Sarrailh, Presidente de la Asamblea General y Rector de la Universidad de París, hizo un cálido elogio de la obra eminentemente educacional de nuestro gobierno, mencionando la creación de la Ciudad Universitaria y señaló de paso también, la obra eminentemente educacional del Sr. Jaime Torres Bodet cuando fungió como director general de la UNESCO".

${ }^{29}$ Jaime Torres Bodet, Memorias, 1981, México, Porrúa, vol. II, p. 318-322. En el informe diplomáti- 
NOTAS

conferencia, se determinó por mayoría de votos que la sede de la tercera Conferencia de la Asociación Internacional de Universidades sería en la Ciudad Universitaria de México, ${ }^{30}$ una victoria más de la diplomacia cultural parlamentaria encabezada por el embajador Torres Bodet.

\section{Conclusión}

Este ensayo procuró acercarse al trabajo diplomático de promoción cultural mexicana del Embajador Jaime Torres Bodet, de 1954 a 1958, en y desde París. Pretendió esclarecer la dificultad por presentar una imagen positiva de México en un "viejo país" como Francia, tan resentido por los efectos de una guerra mundial que terminaba y que vivía la guerra fría con todas sus implicaciones políticas. Esto explica que, a primera vista, la promoción cultural mexicana en París se enfrentara a una indiferencia enorme. Es ilustrativa a este respecto la pregunta de la esposa de Pierre Brisson,

co ya citado se menciona que "los delegados Jaime Torres Bodet y Luis Garrido, participaron en varias discusiones de carácter técnico teniendo siempre éxito en esas actuaciones".

${ }^{30}$ Ibid., p. 7. Se menciona en el anterior documento que "la Ciudad de México fue señalada como sede de la próxima Conferencia a petición del delegado de México el embajador Jaime Torres Bodet y electo el Lic. Nabor Carrillo Flores, rector de la UNAM como miembro del Comité Organizador". director del periódico Le Figaro, al embajador de México, a bordo del barco que los conducía a París: “¿Hay acaso una Embajada de México en París?" 31

Una posible conclusión, en primer lugar, es señalar el prestigio enorme del que gozaba Torres Bodet después de su paso por la dirección general de la UNESCO, dos años antes de ejercer su cargo como embajador. Fue una inercia que supo aprovechar plenamente para hacer posible su gestión cultural desde la Embajada. El conocimiento profundo de las instituciones diplomáticas e intelectuales y de sus protagonistas fue un instrumento valiosísimo para trabajar bien. Por parte de las instituciones mexicanas, sus amistades en la Secretaría de Relaciones Exteriores (José Gorostiza, subsecretario y antiguo compañero de generación en la revista Contemporáneos), en la Presidencia de la República (Marte R. Gómez, presidente del Consejo de Fomento y Coordinación de la Producción Nacional), en el Colegio de México (con el director Alfonso Reyes), por mencionar sólo algunas, permitieron tener todo el respaldo institucional que requerían sus ambiciosos proyectos.

Otra conclusión posible acerca del éxito innegable del embajador de

${ }^{31}$ Jaime Torres Bodet, Memorias, op cit., vol. II, p. 345. 
México en su diplomacia cultural es el amor tan profundo, casi religioso, que profesaba hacia las letras mexicanas y francesas. Comentando el éxito de la exposición de libros franceses, escribe en sus Memorias: "Debo confesar que me sentí conmovido al ver, junto a los libros de mis amigos mexicanos, como Enrique González Martínez, Antonio Caso, José Vasconcelos, Alfonso Reyes, Carlos Pellicer, José Gorostiza, Salvador Novo, algunos autógrafos de mis amigos franceses: Georges Duhamel, André Maurois, Jules Supervielle, y Paul Valery [...] Muertos o vivos, todos ellos me ayudarían en la tarea de afirmar - por el espíritu y para el espíritu- la comprensión humana de nuestros pueblos". Torres Bodet había hecho de Francia su "tierra de elección intelectual", no sin dejar de amar profundamente a su propia cultura. Esto explica que la diplomacia de Francia viera en el antiguo director de la UNESCO un "defensor de la cultura francesa". ${ }^{32}$ Promover a la cultura mexicana en París equivalía a enaltecer la francesa. En un

${ }^{32}$ El 16 de diciembre de 1952, poco después de renunciar a su cargo en la UNESCO, el presidente francés, al entregarle personalmente la Gran Cruz de la Legión de Honor, condecoración más alta que otorga el gobierno francés, mencionó que Torres Bodet, había "servido a la cultura francesa" y "había enriquecido su patrimonio cultural". Cfr. Torres Bodet, Memorias, op. cit., vol. II, p. 237. contexto de crisis de identidad, de lucha ideológica de guerra fría y de descolonización que debilitaba al país amigo, Torres Bodet, "le Chateaubriand Mexicain", ${ }^{33}$ embajador de un país con gran liderazgo en la América latina en la segunda posguerra mundial, supo "enamorar" a Francia acudiendo, como su maestro Alfonso Reyes, a un viejo y probado recurso: "la fuerza de la belleza". ${ }^{34}$ Lo hizo promoviendo lo que quizá sea el más profundo orgullo francés, su literatura. Esto permitió abrir muchas puertas y dio lugar a una tarea de diplomacia cultural o de diplomacia a secas, con un rotundo éxito. Por eso, Jaime Torres Bodet difundió una imagen tan atractiva de México y su cultura que, al terminar su mandato como embajador en 1958, "podía pensarse que México estaba de moda". 35 
CITAM Derechos Reservados.

La reproducción total o parcial de este artículo se podrá hacer si el ITAM otorga la autorización previamente por escrito. 